\title{
The diabetes gene $P d x 1$ regulates the transcriptional network of pancreatic endocrine progenitor cells in mice
}

\author{
Jennifer M. Oliver-Krasinski,1,2 Margaret T. Kasner,2 Juxiang Yang,,1,2 Michael F. Crutchlow,1,2 \\ Anil K. Rustgi, ${ }^{2,3}$ Klaus H. Kaestner, ${ }^{1,3}$ and Doris A. Stoffers ${ }^{1,2}$ \\ ${ }^{1}$ Institute for Diabetes, Obesity and Metabolism, 2Department of Medicine, and ${ }^{3}$ Department of Genetics, \\ University of Pennsylvania School of Medicine, Philadelphia, Pennsylvania, USA.
}

\begin{abstract}
Heterozygous mutations in the gene encoding the pancreatic homeodomain transcription factor pancreatic duodenal homeobox 1 (PDX1) are associated with maturity onset diabetes of the young, type 4 (MODY4) and type 2 diabetes. Pdx 1 governs the early embryonic development of the pancreas and the later differentiation of the insulin-producing islet $\beta$ cells of the endocrine compartment. We derived a $P d x 1$ hypomorphic allele that reveals a role for $\mathrm{Pdx} 1$ in the specification of endocrine progenitors. Mice homozygous for this allele displayed a selective reduction in endocrine lineages associated with decreased numbers of endocrine progenitors and a marked reduction in levels of mRNA encoding the proendocrine transcription factor neurogenin 3 (Ngn3). During development, Pdx1 occupies an evolutionarily conserved enhancer region of $\mathrm{Ngn} 3$ and interacts with the transcription factor one cut homeobox 1 (Hnf6) to activate this enhancer. Furthermore, mRNA levels of all 4 members of the transcription factor network that regulates $\mathrm{Ngn} 3$ expression, SRY-box containing gene 9 (Sox9), Hnf6, Hnf1b, and forkhead box A2 (Foxa2), were decreased in homozygous mice. Pdx1 also occupied regulatory sequences in Foxa 2 and $\mathrm{Hnf} 1 \mathrm{~b}$. Thus, $\mathrm{Pdx} 1$ contributes to specification of endocrine progenitors both by regulating expression of $\mathrm{Ngn} 3$ directly and by participating in a cross-regulatory transcription factor network during early pancreas development. These results provide insights that may be applicable to $\beta$ cell replacement strategies involving the guided differentiation of ES cells or other progenitor cell types into the $\beta$ cell lineage, and they suggest a molecular mechanism whereby human PDX1 mutations cause diabetes.
\end{abstract}

\section{Introduction}

Insulin deficiency due to reduced pancreatic islet $\beta$ cell number underlies the progression of both type 1 and type 2 diabetes, prompting efforts to develop $\beta$ cell replacement therapies. The high hopes for human islet transplantation as such a therapy have been tempered by their limited availability and short-term function after transplantation, resulting in an intense focus on the development of alternate sources of $\beta$ cells, through the guided differentiation of stem or progenitor cells or the transdifferentiation of more abundant mature cells. Transdifferentiation approaches have focused largely on the expression of a single or a combination of transcription factors that drive $\beta$ cell development and differentiation and most have relied, at least in part, upon pancreatic duodenal homeobox 1 ( $\mathrm{Pdx} 1)$, a homeodomain transcription factor with critical regulatory roles in early pancreas development and in the mature $\beta$ cell (1-5). Recent advances in the derivation of insulin-expressing $\beta$-like cells from ES cells (6-11) have also been guided by the principles of embryonic pancreas development (reviewed in ref. 12). Clinical translation of these approaches, however, will require improvements in efficiency, fidelity, and stability of generating the $\beta$ cell phenotype, efforts which will likely be informed by the identification of novel factors and regulatory relationships in embryonic pancreas development.

Conflict of interest: The authors have declared that no conflict of interest exists. Nonstandard abbreviations used: Ngn3, neurogenin 3; PDC, pancreatic ductal cell; Pdx1, pancreatic duodenal homeobox 1.

Citation for this article: J. Clin. Invest. 119:1888-1898 (2009). doi:10.1172/JCI37028.
The embryonic development of islet $\beta$ cells is critically dependent on the function of the basic helix-loop-helix transcription factor neurogenin 3 (Ngn3). Genetic lineage-tracing studies and the phenotype of Ngn3-null mice demonstrate that all islet hormone-producing endocrine cell types $(\alpha, \beta, \delta$, pancreatic polypeptide, $\varepsilon)$ derive from Ngn3-expressing progenitors (13-20). Ngn3 is first observed in a subpopulation of pancreatic epithelial cells at E9.5, and its expression is coordinated by the Notch signaling pathway $(13,18$, 21) and a transcription factor coregulatory network comprised of SRY-box containing gene 9 (Sox9), one cut homeobox 1 (Hnf6), Hnf1b, and forkhead box A2 (Foxa2) (22). Pdx1 (also known as IPF1, IDX1, STF1, and XlhBox8) is a homeodomain transcription factor expressed throughout the pancreatic epithelium at E9.0 that is critically required for organogenesis in mice and humans (23-28).

The concept that $\mathrm{Pdx} 1$ is upstream of $\mathrm{Ngn} 3$ during embryonic development is based on genetic lineage-tracing studies, indicating that Pdx1-expressing progenitors give rise to both exocrine and endocrine lineages, while the progeny of Ngn3-expressing progenitors selectively populate the endocrine compartment $(16,29)$. Further support derives from the marked reduction or absence of the endocrine compartment in both Ngn3 and Pdx1 loss-of-function alleles as well as the broader phenotype of Pdx1 loss of function that includes arrested development of the exocrine compartment $(13,24,25)$. However, close examination of these early embryonic phenotypes reveals that the endocrine compartment requires Ngn3 but is not fully dependent upon Pdx1. The arrested dorsal ductule in $P d x 1^{-/-}$mice still contains the early hormone-expressing cells at E9.5, characteristic of the primary transition, whereas $\mathrm{Ngn}^{-/-}$mice lack both first and second wave endocrine differentiation, sug- 

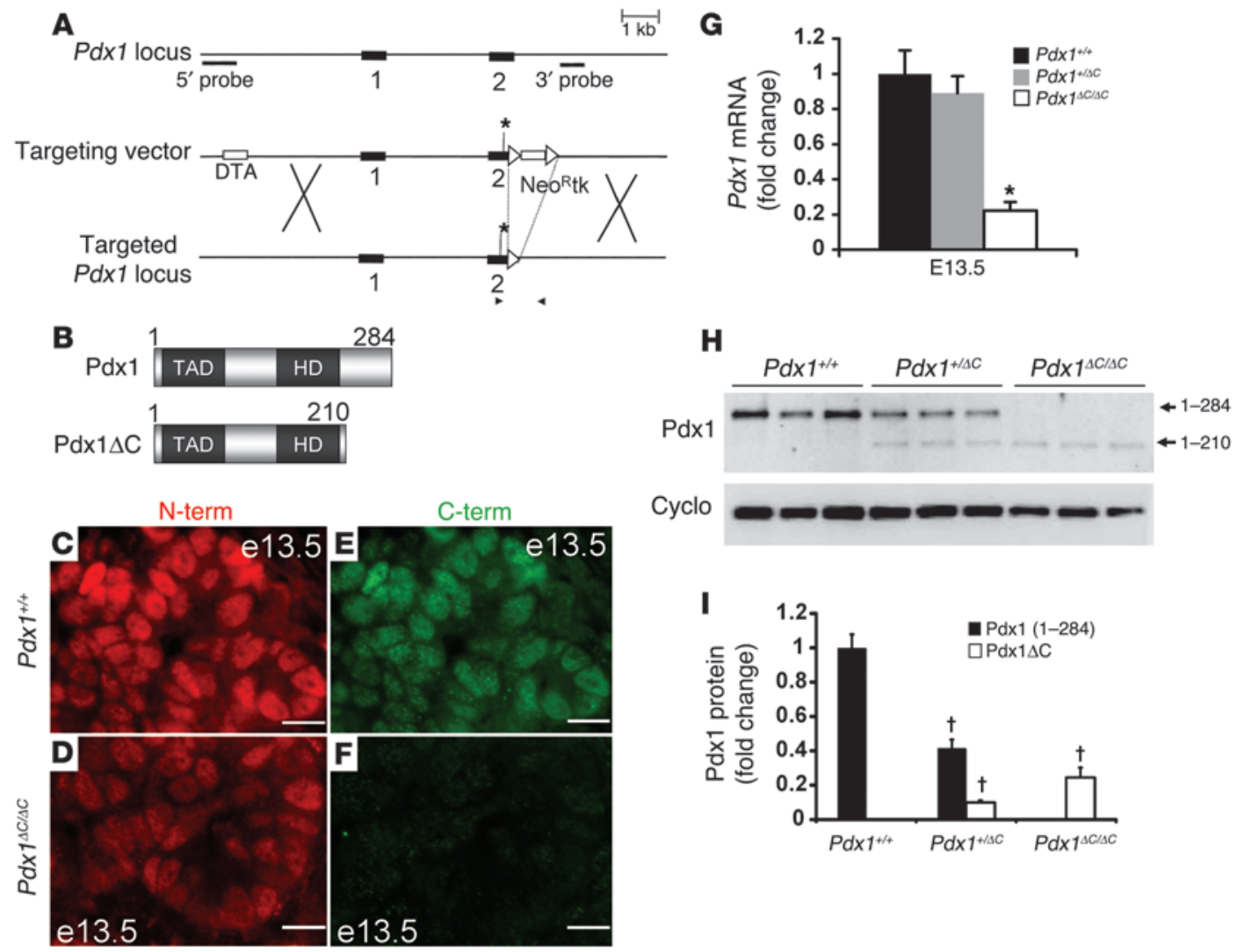

\section{Figure 1}

Derivation of $P d x 1^{\Delta C / \Delta C}$ mice. (A) Targeting strategy to replace the codon encoding Ser210 in the mouse $P d x 1$ locus with a termination codon (asterisk), thereby preventing translation of the $\mathrm{C}$ terminus. Schematic shows both exons (black rectangles), the $5^{\prime}$ diphtheria toxin $\mathrm{A}(D T A)$ gene, and the loxP-flanked $3^{\prime}$ neomycin resistance-thymidine kinase $\left(\mathrm{NeO}^{R}\right.$-tk) cassettes (white rectangles). Black arrows indicate the location of genotyping primers. White arrows denote the location of loxP sites. $\mathrm{X}$ indicates sites of homologous recombination. (B) Predicted domain structure of the truncated $P d x 1(1-210)$ protein, termed $P d x 1 \Delta C$, is represented below the wild-type full-length form of $P d x 1(1-284)$. TAD, transactivation domain; HD, homeodomain. (C-F) $P d x 1^{+/+}$and $P d x 1^{\Delta C / \Delta C}$ E13.5 pancreas stained with antisera raised against either $\mathrm{N}$-terminal (N-term; red) or C-terminal (C-term; green) Pdx1 epitopes. Scale bar: $10 \mu \mathrm{m}$. (G) $P d x 1$ mRNA levels in total pancreas from $P d x 1^{+/+}, P d x 1^{+/ \Delta C}$, and $P d x 1^{\Delta C / \Delta C}$ pancreata measured at E13.5 ( $n=7-8$ per genotype; $\left.{ }^{*} P=0.0001\right)$. (H) Representative Western blot of E13.5 total pancreas protein from $P d x 1^{\Delta C / \Delta C}, P d x 1^{+/ \Delta C}$, and $P d x 1^{+/+}$littermate controls using $\mathrm{N}$-terminal-specific $\mathrm{Pdx} 1$ (top panel) and cyclophilin $\mathrm{B}$ (cyclo; bottom panel) antisera. Both full-length $\mathrm{Pdx} 1$ and truncated $\mathrm{Pdx} 1 \Delta \mathrm{C}$ are indicated. Quantitation from 3 separate Western blots $(n=9$ animals per group) is shown in $\mathbf{I} .{ }^{\dagger} P<0.00001$.

gesting that $\mathrm{Pdx} 1$ is specifically required only for the second wave $(13,25)$. Further, it is not clear from these studies whether Pdx1 is required directly for the emergence, maintenance, or differentiation of endocrine progenitors or only indirectly through its critical role in the formation of the pancreatic progenitor cells from which these cells emerge.

Heterozygous $P d x 1$ mutations are associated with early (MODY4) and late onset forms of type 2 diabetes (reviewed in ref. 30). Some of these mutations occur in the evolutionarily conserved but poorly characterized $\mathrm{C}$ terminus; these mutations are associated with modest decreases in transactivation (31-33). The $\mathrm{C}$ terminus is not essential for DNA binding but is required for normal activation of target gene promoters $(34,35)$, perhaps through its interactions with 2 recently identified protein partners, Pcif1 and Meis1a, whose roles in the pancreatic $\beta$ cell have yet to be determined (36-38). Therefore, to determine the in vivo role of the Pdx1 C-terminal domain, we derived a Pdx1 hypomorphic allele harboring a premature truncation mutation of the $\mathrm{C}$ terminus $(P d x 1 \Delta \mathrm{C})$ and there- by uncovered a direct role for $\mathrm{Pdx} 1$ in the specification of $\mathrm{Ngn}^{+}$ endocrine progenitors. $\mathrm{Pdx} 1$ contributes to the specification of endocrine progenitors by regulating Ngn3 directly in concert with Hnf6, which we identified as a partner of the $\mathrm{C}$ terminus, and by participating in a cross-regulatory network during early pancreas development. These new insights into the role of $\mathrm{Pdx} 1$ to promote the transition from pancreatic progenitor to endocrine progenitor have the potential to impact on the generation of $\beta$ cell replacements for regenerative medicine and islet transplantation.

\section{Results}

Derivation of hypomorphic $P d x 1^{\Delta C / \Delta C}$ mice. We engineered a $P d x 1$ targeting vector containing exon 1 and a mutated exon 2 , in which the codon encoding Ser 210 was replaced by a termination codon (Figure $1 \mathrm{~A})$. The resulting 210 -amino acid $\mathrm{Pdx} 1$ protein, termed $\operatorname{Pdx} 1 \Delta \mathrm{C}$ (Figure 1B), was detected in pancreata from homozygous $P d x 1^{\Delta C / \Delta C}$ mice at E13.5 (Figure $1 C$ ) by immunostaining with $\mathrm{N}$-terminal-specific antisera. The absence of $\mathrm{Pdx} 1$ staining using 
A

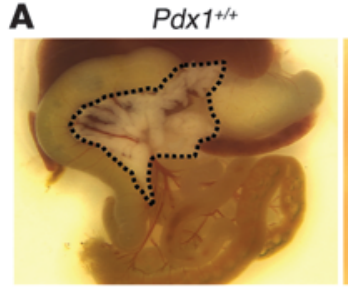

B

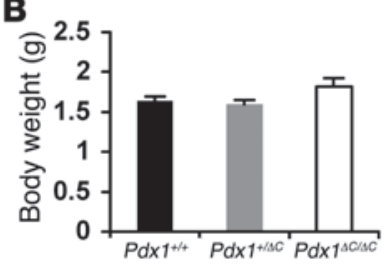

D

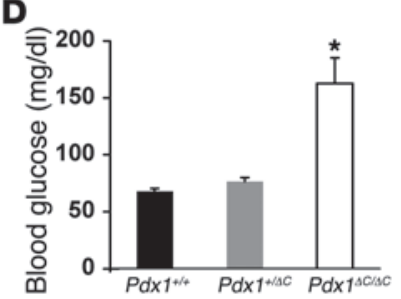

$\mathbf{E}$
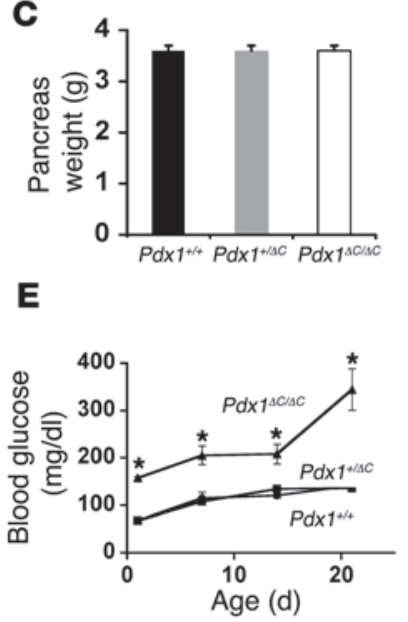

$\mathbf{F}$

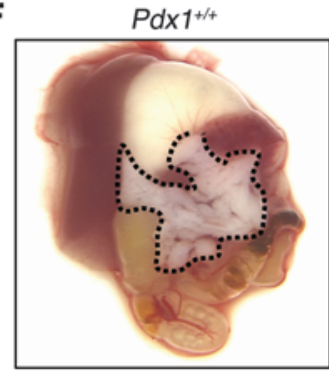

G

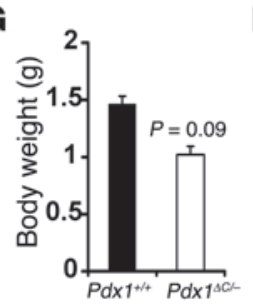

H
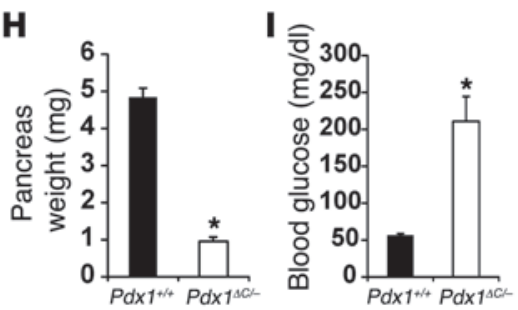

C-terminal-specific antisera confirmed that the Pdx1 C terminus is not translated in $P d x 1^{\Delta C / \Delta C}$ mice (Figure $1 \mathrm{~F}$ ). $\mathrm{Pdx} 1$ immunoreactivity was visibly reduced at E13.5 in homozygous mutant mice compared with that of littermate controls. Quantitative Western blot analysis indicated a $75 \%$ reduction in $\mathrm{Pdx} 1$ protein levels in E13.5 $P d x 1^{\Delta C / \Delta C}$ pancreata compared with that of littermate controls (Figure 1, $\mathrm{H}$ and I). $P d x 1^{\Delta C / \Delta C}$ mice displayed a similar reduction in pancreatic Pdx1 mRNA at E13.5 (Figure 1G), which may indicate a role for the C terminus in Pdx1 autoregulation (39, 40). Alternatively, the introduction of the nonsense mutation may have influenced $P d x 1$ mRNA stability, although this is less likely given the location of the mutation. Terminal exon nonsense mutations, such as the one we have generated, are generally resistant to nonsense-mediated RNA decay. By contrast, $P d x 1^{+/-}$mice displayed $38 \%$ and $42 \%$ reduction in $\mathrm{Pdx} 1$ protein and transcript

\section{Figure 2}

Dose-dependent regulation of pancreas organogenesis. (A-E) Normal pancreas organogenesis in $P d x 1^{\Delta C / \Delta C}$ mice. (A) Foregut and accessory organs were dissected from newborn animals. The pancreas is highlighted by a black dotted line. (B) Body weights and (C) pancreatic weights were also measured at P1 ( $n=6-15$ per group). ( $\mathbf{D}$ and E) Development of overt diabetes in $P d x 1^{\Delta C / \Delta C}$ mice. (D) Random blood glucose levels were measured at birth and (E) followed for 3 weeks in $P d x 1^{\Delta C / \Delta C}$ (triangles), $P d x 1^{+/ \Delta C}$ (squares), and $P d x 1^{+/+}$(circles) littermates ( $n=6-21$ per group; * $P<0.003$ compared with both other groups). ( $F-I)$ Pancreatic hypoplasia in $P d \times 1^{\Delta C /}$ - mice. (F) Foregut and accessory organs were dissected from newborn animals. The pancreata from wild-type (left panel) and $P d x 1^{\Delta C /}$ (right panel) mice are highlighted by the black dotted line. (G) Body weights, $(\mathbf{H})$ pancreatic weights, and (I) random blood glucose levels were measured in wild-type and $P d x 1^{\Delta C /}$ - littermates at P1 $\left(n=5\right.$ per group; $\left.{ }^{*} P<0.003\right)$.

levels, respectively, compared with littermate controls (Supplemental Figure 1), similar to the $32 \%$ reduction in $\mathrm{Pdx} 1$ protein levels observed in adult islets isolated from these mice (41). Thus, hypomorphic $P d x 1^{\Delta C / \Delta C}$ mice express lower Pdx1 protein levels at E13.5 compared with $P d x 1^{+/-}$mice.

Global defect in pancreatic endocrine development in $P d x 1^{\Delta C / \Delta C}$ mice. $P d x 1^{\Delta C / \Delta C}$ mice were born in the expected Mendelian ratios, with normal body and pancreatic weights and grossly normal pancreatic appearance (Figure 2, $\mathrm{A}-\mathrm{C}$ ), indicating that the $\mathrm{C}$ terminus is not required for pancreas organogenesis. To evaluate the influence of further reductions in gene dosage, we crossed $P d x 1^{+/ \Delta C}$ and $P d x 1^{+/-}$mice. At birth, $P d x 1^{\Delta C /-}$ progeny displayed a trend toward reduced body weight and a marked reduction in pancreatic size and weight (Figure 2, F-H), revealing an intermediate phenotype between $P d x 1^{\Delta C / \Delta C}$ and $P d x 1^{-/-}$mice and indicating the threshold at which pancreatic organogenesis becomes sensitive to changes in gene dosage.

Similar to $P d x 1^{\Delta C /-}$ animals, $P d x 1^{\Delta C / \Delta C}$ mice were mildly hyperglycemic at birth, with random blood glucose levels of $157 \pm 3 \mathrm{mg} / \mathrm{dl}$ compared with $67 \pm 3$ $\mathrm{mg} / \mathrm{dl}$ in heterozygous $P d x 1^{+/ \Delta C}$ mice and $68 \pm 4 \mathrm{mg} /$ $\mathrm{dl}$ in wild-type $P d x 1^{+/+}$mice (Figure 2, D and I). By 3 weeks of age, $P d x 1^{\Delta C / \Delta C}$ mice progressed to marked hyperglyce$\mathrm{mia}$, with random blood glucose levels of $344 \pm 44 \mathrm{mg} / \mathrm{dl}$ compared with $141 \pm 9 \mathrm{mg} / \mathrm{dl}$ in $P d x 1^{+/ \Delta C}$ and $136 \pm 6 \mathrm{mg} / \mathrm{dl}$ in $P d x 1^{+/+}$ mice (Figure $2 \mathrm{E}$ ). At this age, total body and pancreatic weights in $P d x 1^{\Delta C / \Delta C}$ mice were unchanged compared with wild-type animals (data not shown). Intraperitoneal glucose tolerance tests performed in male and female mice at 3-4 weeks of age revealed overt diabetes in $P d x 1^{\Delta C / \Delta C}$ mice of both genders. Similar to $P d x 1^{+/-}$mice $(41,42)$, heterozygous male $P d x 1^{+/ \Delta C}$ mice were glucose intolerant, whereas female $P d x 1^{+/ \Delta C}$ mice had normal glucose tolerance at this age (Figure 3, A and B). Consistent with their diabetic phenotype, male and female $P d x 1^{\Delta C / \Delta C}$ mice demonstrated a reduction in fasting plasma insulin and complete loss of the glucose-stimulated increase in plasma insulin. Male $P d x 1^{+/ \Delta C}$ mice showed a selective loss of the glucose-stimulated increase in plasma insulin, whereas 

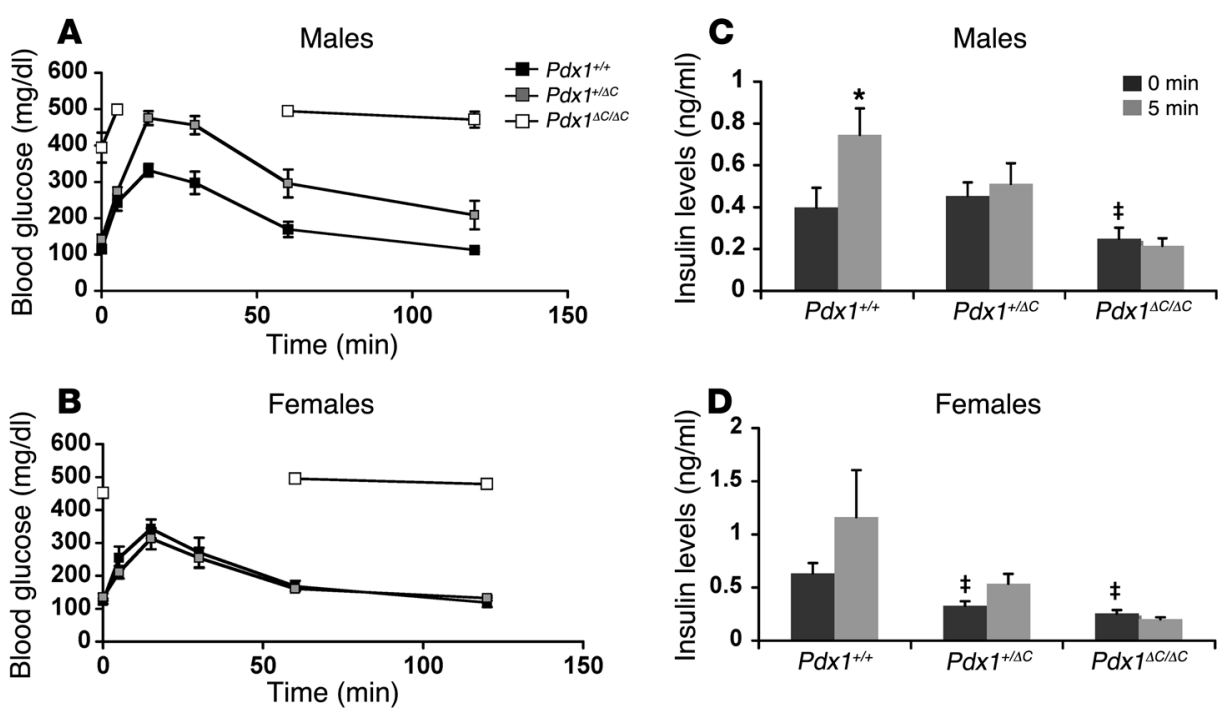

Figure 3

Impaired glucose tolerance and insulin secretion in $P d x 1^{\Delta \mathrm{C}}$ mice. (A and $\left.\mathbf{B}\right)$ Glucose tolerance in male (A) and female (B) mice. Intraperitoneal glucose tolerance tests using $2 \mathrm{~g}$ glucose/kg body weight performed on 3- to 4-week-old mice ( $n=4-7$ per group; ANOVA; male $P d x 1^{+/+}$versus $P d x 1^{+/ \Delta C}$, $P=0.0037$; male $P d x 1^{+/+}$versus $P d x 1^{\Delta C / \Delta C}, P<0.0001$; male $P d x 1^{+/ \Delta C}$ versus $P d x 1^{\Delta C / \Delta C}, P<0.0001$; female $P d x 1^{+/+}$versus $P d x 1^{+/ \Delta C}, P=$ NS; female $P d x 1^{+/+}$versus $P d x 1^{\Delta C / \Delta C}, P<0.0001$; female $P d x 1^{+/ \Delta C}$ versus $\left.P d x 1^{\Delta C / \Delta C}, P<0.0001\right)$. Glucose levels in $P d x 1^{\Delta C / \Delta C}$ mice rose above $500 \mathrm{mg} / \mathrm{dl}$, the limit of detection of the handheld glucometer. (C and D) Blunted acute insulin release in $P d \times 1^{\Delta C / \Delta C}$ animals. Insulin levels were measured from whole blood collected at 0 and 5 minutes after intraperitoneal glucose injection ( 2 g glucose/kg body weight). Both male (C) and female (D) mice were 3-4 weeks of age ( $n=4-7$ animals per group). ${ }^{*} P<0.05$ compared with level at 0 minutes after injection of same genotype; $¥ P<0.05$ compared with level at 0 minutes after injection of wild-type mice.

female $P d x 1^{+/ \Delta C}$ mice had a reduction in fasting insulin levels but retained glucose responsiveness (Figure 3, $\mathrm{C}$ and $\mathrm{D}$ ).

To determine whether a defect in $\beta$ cell development could account for the hyperglycemia in $P d x 1^{\Delta C / \Delta C}$ mice, we first measured $\beta$ cell area during embryonic development. At E17.5, a marked reduction in the pancreatic area occupied by $\beta$ cells was observed in $P d x 1^{\Delta C / \Delta C}$ mice (Figure $4, A$ and $B$ ), which persisted in newborn animals. Heterozygous $P d x 1^{+/ \Delta C}$ mice also displayed a reduction in $\beta$ cell area, revealing a gene dosage effect. We evaluated rates of $\beta$ cell replication and apoptosis at E19.5 and found no differences among the genotypes (data not shown). To assess whether the decrease in $\beta$ cell area at E17.5 reflected a $\beta$ cell-specific or a general endocrine defect, we determined the area occupied by the other 4 endocrine cell types ( $\alpha, \delta$, $\varepsilon$, pancreatic polypeptide). Interestingly, in $P d x 1^{\Delta C / \Delta C}$ mice, there was a global reduction in endocrine lineages, although $\beta$ and $\alpha$ cells were more severely affected (Figure $4 \mathrm{C}$ ). Only $\beta$ cell area was reduced in $P d x 1^{+/ \Delta C}$ mice, indicating a greater sensitivity of the $\beta$ cell lineage to $\mathrm{Pdx} 1$ expression level and function. Moreover, transcript levels for the endocrine lineage-specific hormones and transcription factors were all reduced at E13.5 during the secondary transition (Supplemental Figure 2). To exclude the possibility that an overall reduction in the pancreatic epithelium accounts for the reduction in the endocrine compartment in $P d x 1^{\Delta C / \Delta C}$ embryos, we measured epithelial area at E11.5 and E13.5 (Figure 4D). No differences were observed in $P d x 1^{\Delta C / \Delta C}$ embryos, which is consistent with the normal levels of Ptf1a and Hnf4a mRNA at E13.5 (Figure 4E) and with normal pancreatic weight at P1 (Figure 2C). Altogether, these data indicated that Ngn3-independent mechanisms contributed to the reduction in $\beta$ cell area observed in $P d x 1^{+/ \Delta C}$ mice (Figure $4, B$ and $G$ ).

To determine whether decreased proliferation of Ngn3-expressing progenitors accounts for the reduced numbers in $P d x 1^{\Delta C / \Delta C}$ animals, we performed double immunofluorescence for $\mathrm{Ngn} 3$ and Ki67 (Figure 4H). At E11.5, we did not observe any $\mathrm{Ki}^{+} 7^{+} \mathrm{Ngn} 3^{+}$ cells (data not shown), likely due to the very low number of $\mathrm{Ngn}^{+}$ cells present at this age. At E13.5 and E15.5, proliferation rates of $\mathrm{Ngn}^{+}$cells were normal in $P d x 1^{\Delta C / \Delta C}$ and $P d x 1^{+/ \Delta C}$ mice (Figure 4I, left and center panels). Results were confirmed by BrdU incorporation at E15.5 (Figure 4I, right panel).

To determine whether decreased survival contributed to the reduction in $\mathrm{Ngn}^{+}$cell number, we performed double immunofluorescence for TUNEL and Ngn3. At E11.5 and E13.5, $\mathrm{TUNEL}^{+} \mathrm{Ngn}^{+}$cells were not detected in any group. At E15.5, no significant difference in apoptotic rates of $\mathrm{Ngn}^{+}$cells was observed in $P d x 1^{\Delta C / \Delta C}$ mice compared with that in littermate controls (Supplemental Table 1). Although the number of $\mathrm{TUNEL}^{+}$cells at E19.5 was extremely low, we did observe an increase in the number of apoptotic $\mathrm{Ngn}^{+}$cells at this age in both $P d x 1^{\Delta C / \Delta C}$ and $P d x 1^{+/ \Delta C}$ animals (Supplemental Figure 3 and Supplemental Table 1), indicating that $\mathrm{Pdx} 1$ could be important in maintaining survival of the Ngn3 progenitor population during late gestation. This is in agreement with the more pronounced and progressive reduction in the number of $\mathrm{Ngn}^{+}$cells in $P d x 1^{\Delta \mathrm{C} / \Delta \mathrm{C}}$ mice relative to $P d x 1^{+/+}$ mice, beginning at E17.5 (Figure 4, G and inset). Although Pdx1 was not coexpressed with Ngn3 at this age (Supplemental Figure 4), appearing to rule out a cell autonomous mechanism, it could regu- 
A
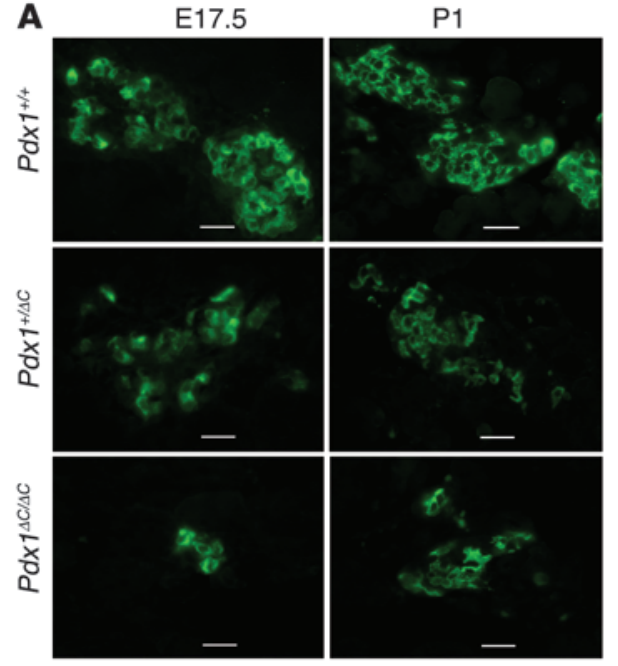

Insulin

F

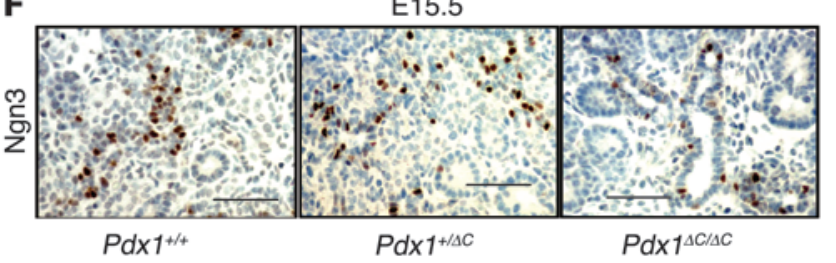

$P d x 1^{+/+}$

H

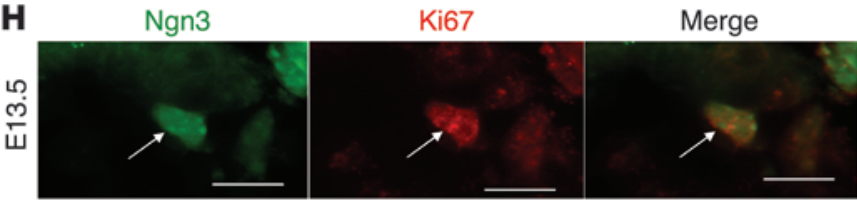

$\mathbf{B}$
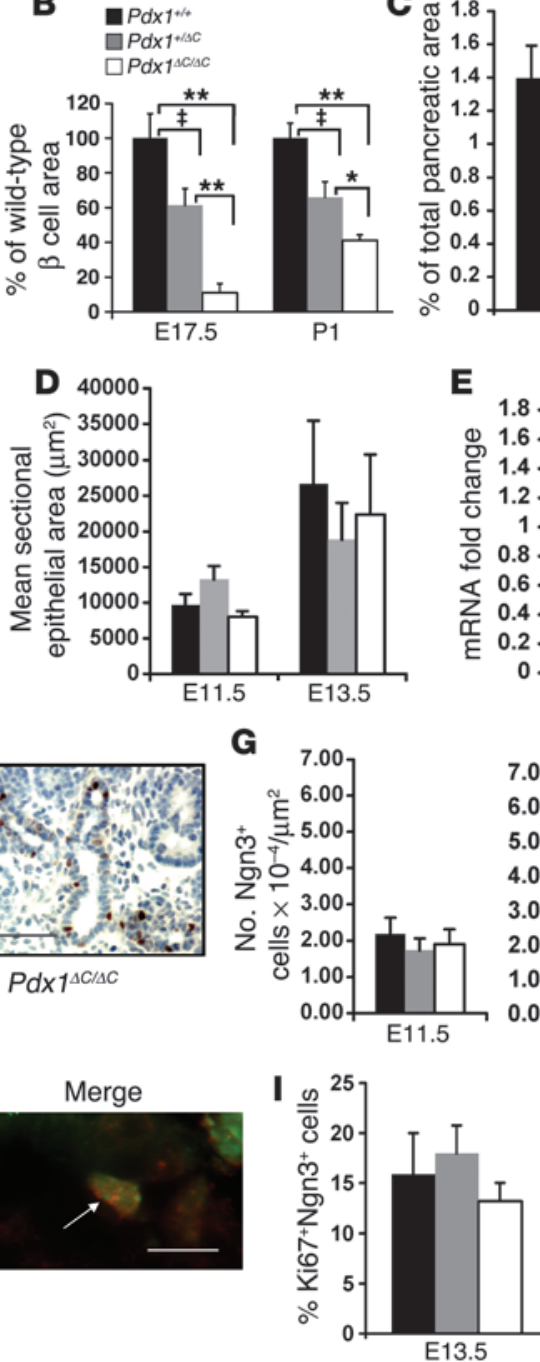

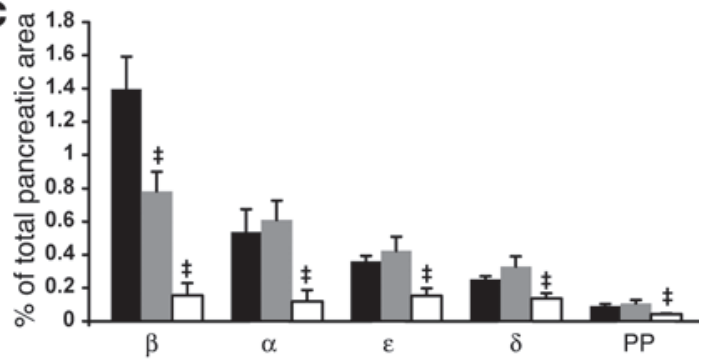

E
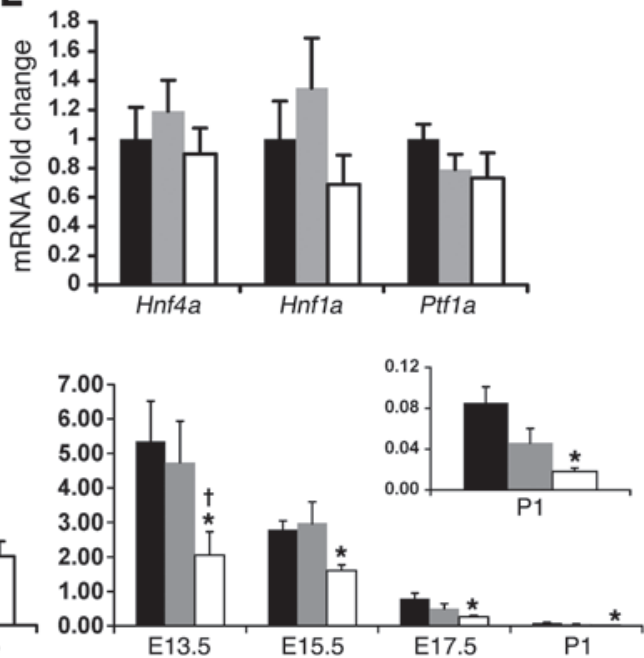

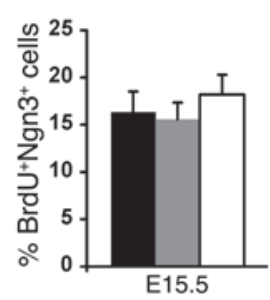

Figure 4

Specific defect in endocrine progenitor specification in $P d x 1^{\Delta C / \Delta C}$ mice. (A-C) Global reduction in endocrine lineages at $E 17.5$ in $P d x 1 \Delta C / \Delta C$ mice. (A) Immunofluorescence for insulin (green). Scale bar: $20 \mu \mathrm{m}$. (B) Pancreatic area occupied by insulin-positive $\beta$ cells. Values are expressed relative to wild-type mice $\left(n=5-9\right.$ per genotype; ${ }^{*} P<0.05$, $\left.{ }^{* *} P<0.0005,{ }^{\ddagger} P<0.05\right)$. (C) Percentage pancreatic area at E17.5 occupied by the 5 endocrine cell types ( $n=6-8$ animals per genotype, 3 sections per animal; $\ddagger P<0.05$ compared with both other groups). PP, pancreatic polypeptide. (D and E) Normal epithelial area in $P d x 1^{\Delta C / \Delta C}$ mice. (D) Pancreatic epithelial area measured from 3 (E13.5) or 5 (E11.5) H\&E-stained sections. (E) Relative mRNA levels of Hnf1a, Hnf4a, and Ptf1a in E13.5 pancreas ( $n=7-9$ per genotype). (F and G) Reduction in Ngn3 $3^{+}$pancreatic endocrine progenitor cells in $P d x 1^{\Delta C / \Delta C}$ mice. (F) Immunostaining for Ngn3 (brown) with hematoxylin counterstain (blue). Scale bar: $50 \mu \mathrm{m}$. (G) Number of $\mathrm{Ngn}^{+}$cells per unit of epithelial area (E11.5) or pancreatic area (E13.5-P1) quantified from 3 (E13.5-P1) or 5 (E11.5) tissue sections per animal $\left(n=4-8\right.$ per genotype; ${ }^{*} P<0.05$ compared with wild-type mice; ${ }^{\dagger} P<0.05$ compared with $P d x 1^{+/ \Delta C}$ mice). (H and I) Ngn3 ${ }^{+}$ endocrine progenitors replicate normally in $\mathrm{Pdx} 1^{\Delta C / \Delta C}$ mice. $(\mathbf{H})$ Representative example of Ki67+Ngn3+ double-positive cell. Arrows point to the same cell in all panels. Scale bar: $10 \mu \mathrm{m}$. (I) Percentage of total $\mathrm{Ngn}^{+}$cells that are $\mathrm{Ki}^{2} 7^{+}$or $\mathrm{BrdU}+$; more than $100 \mathrm{Ngn} 3^{+}$cells per animal were counted ( $n=4-5$ per genotype).

late expression of a survival factor by neighboring cells. This is the first report to our knowledge indicating the $\mathrm{Ngn}^{+}$cells undergo apoptosis, albeit at a low rate.

$P d x 1$ directly regulates $\mathrm{Ngn} 3$. Since proliferation and survival rates of $\mathrm{Ngn}^{+}$cells were normal during early development and could not account for the general reduction in $\mathrm{Ngn}^{+}$cell number, we considered that $\mathrm{Pdx} 1$ might regulate the formation of islet progenitors. To determine whether $\mathrm{Pdx} 1$ could influence specification of endocrine progenitors by regulating $\mathrm{Ngn} 3$ at the transcriptional level, we measured Ngn3 mRNA levels at E13.5 and found Ngn3 expression reduced by $80 \%$ in $P d x 1^{\Delta C / \Delta C}$ mice (Figure $5 A$ ). In agreement with the observed reduction in $\mathrm{Ngn} 3$ staining intensity, $\mathrm{Ngn} 3$ transcript levels were reduced out of proportion to the reduction in cell number. $N g n 3 \mathrm{mRNA}$ levels were unaffected in $P d x 1^{+/-}$ mice (Supplemental Figure 1C), indicating a specific role for the $\mathrm{C}$ terminus or a critical threshold of $\mathrm{Pdx} 1$ protein that is required for $N g n 3$ expression. Conversely, a gain-of-function experiment demonstrated that $\mathrm{Pdx} 1$ is sufficient for activation of $\mathrm{Ngn} 3$. Over- 

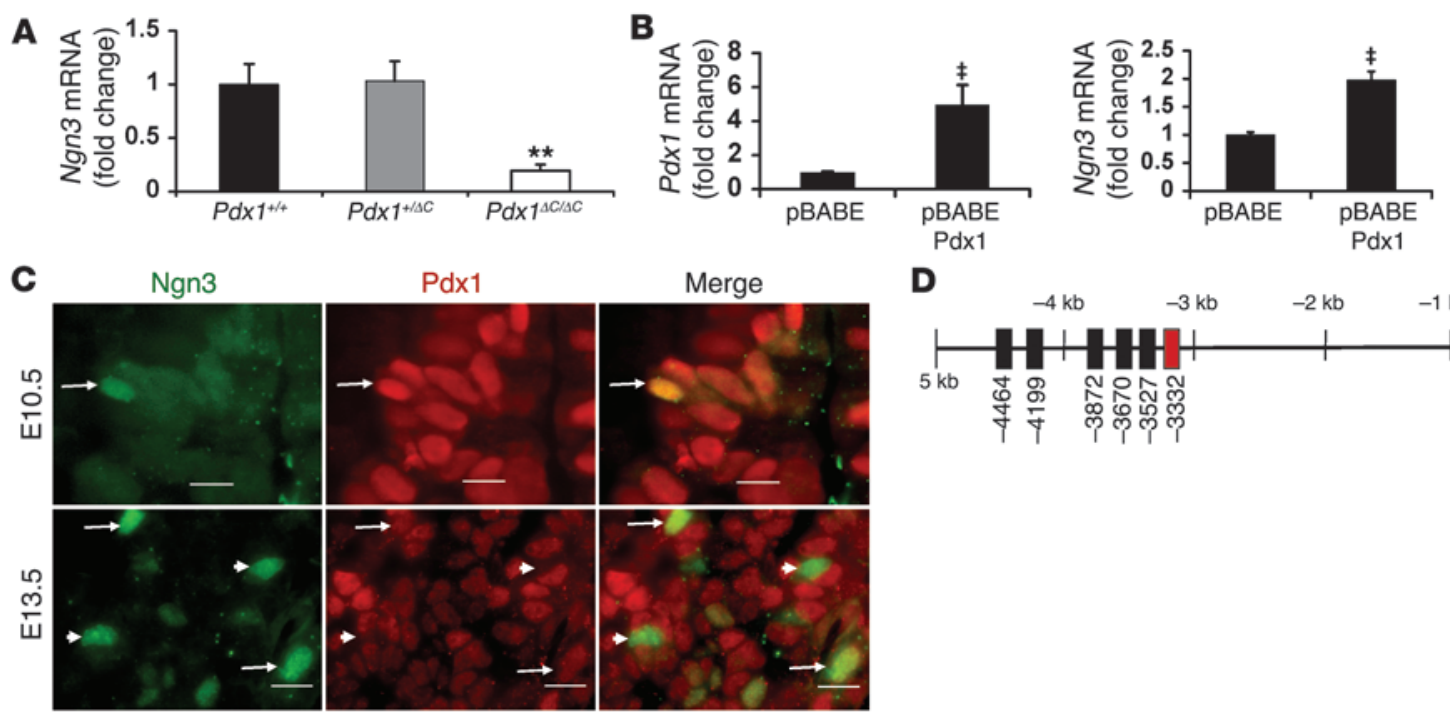

D
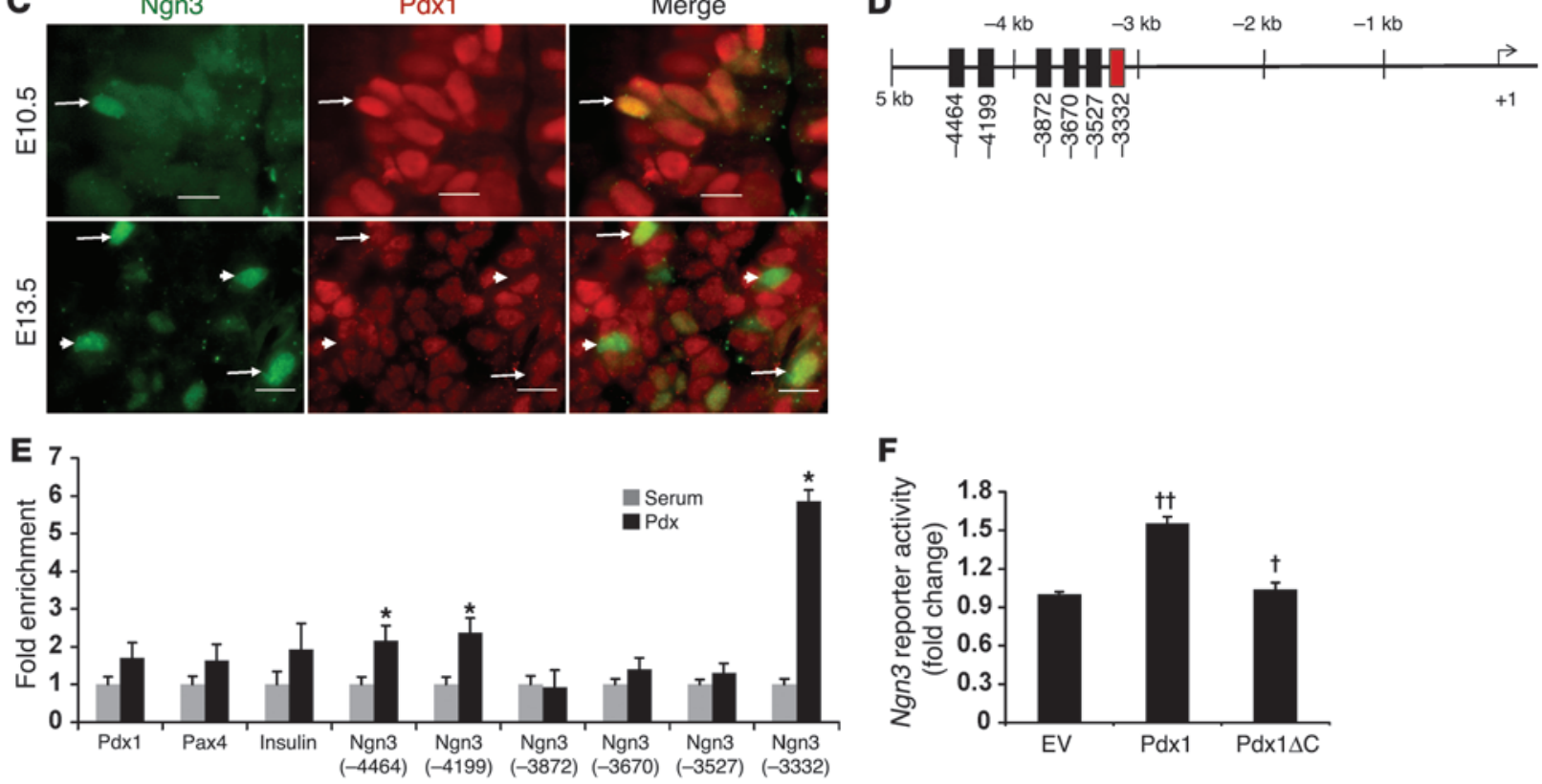

Figure 5

Pdx1 regulates Ngn3, at least in part, via its direct occupancy of a conserved upstream enhancer of $N g n 3$. (A) Ngn3 mRNA levels in total pancreas of E13.5 animals $\left(n=5 ;{ }^{* *} P=0.005\right)$. (B) Expression of Ngn3 in PDCs transduced with pBABE or pBABE-Pdx1 retroviruses. Pdx1 and Ngn3 mRNA levels are expressed compared with empty vector $(n=6 ; \ddagger P<0.007)$. (C) Colocalization of Pdx1 and Ngn3 during pancreas development. Double immunofluorescence for Ngn3 (green) and Pdx1 (red) in wild-type pancreata. Arrows indicate double-positive cells and arrowheads mark singlepositive Ngn3 cells. Scale bar: $10 \mu \mathrm{m}$. (D) Diagram depicting conserved TT/AAT sites in the mouse Ngn3 promoter (black and red boxes). The region homologous to the previously described human Ngn3 Cluster 1 enhancer that contains binding sites for Hnf1, Foxa2, and Hnf6 is indicated in red. (E) ChIP with Pdx1 antisera performed on at least 65 pooled wild-type E13.5 pancreata per experiment $\left(n=3\right.$; $\left.{ }^{*} P<0.05\right)$. (F) Promoter reporter assays were performed in HepG2 cells. Cells were transfected with expression vectors for $\mathrm{Pdx} 1, \mathrm{Pdx} 1 \Delta \mathrm{C}$ or empty vector, and the promoter reporter Ngn3(-3379 to -3227)-tkluc ( $n=3$; $†+P<0.05$ versus empty vector, ${ }^{\dagger} P<0.05$ versus full-length $\left.P \mathrm{dx} 1\right)$.

expression of Pdx1 in mouse pancreatic ductal cells (PDCs) was sufficient to activate endogenous Ngn3 mRNA levels as compared with cells transduced with the empty vector (Figure 5B).

The reduction in Ngn3 protein and Ngn3 mRNA in $P d x 1^{\Delta C / \Delta C}$ mice as well as the upregulation of $\mathrm{Ngn} 3$ by $\mathrm{Pdx} 1$ overexpression in heterologous cells suggested that Ngn3 expression is regulated directly or indirectly by Pdx1. In considering the possibility that Pdx1 directly regulates $N g n 3$, we first determined whether and when Pdx1 and Ngn3 are coexpressed, because the evidence for colocalization has been conflicting $(14,15)$. At E10.5, few $\mathrm{Ngn}^{+}$ cells were observed; however, all $\mathrm{Ngn}^{+}$cells at this stage also coexpressed Pdx1 (Figure 5C). By E13.5, a subpopulation of $\mathrm{Ngn}^{+}$cells no longer costained for $\mathrm{Pdx} 1$, suggesting that $\mathrm{Pdx} 1$ expression is not maintained in this population. Consistent with this notion, no $\mathrm{Ngn}^{+} \mathrm{Pdx} 1^{+}$cells were observed at E15.5 and E19.5 (Supplemental Figure 4 and data not shown).

Having determined that Pdx1 expression marks the early $\mathrm{Ngn}^{+}$ islet progenitor, we sought to assess whether Pdx1 could directly regulate Ngn3 transcription. We performed a genomic database search and identified 12 evolutionarily conserved putative Pdx1- binding sites (TT/AAT) clustered in 6 areas of $5 \mathrm{~kb}$ of the proximal mouse Ngn3 promoter (Figure 5D). To determine whether Pdx1 bound any of these sites in vivo, we performed Pdx1 ChIP using wild-type E13.5 pancreata. A 6-fold enrichment of Pdx1 occupancy was detected for Cluster 1 (-3,332; Figure 5E), a conserved enhancer region that was previously described in the human $\mathrm{Ngn} 3$ promoter to contain DNA-binding sites for Hnf1, Hnf6, and Foxa2 (43). No enrichment was detected at other previously described Pdx1-binding sites in the Pax4 and $P d x 1$ promoters $(39,40,44,45)$, suggesting that $\mathrm{Pdx} 1$ does not access the chromatin surrounding these promoters at E13.5. Moreover, few insulin-positive cells are present at this age, and the sensitivity of the assay may be insufficient to measure Pdx1 occupancy at the insulin promoter. To determine whether Pdx1 regulates the activity of this Ngn3 enhancer, we performed Ngn3 enhancer luciferase reporter assays in HepG2 cells. $\mathrm{Pdx} 1$ modestly transactivated the Ngn3 enhancer, while truncated $\operatorname{Pdx} 1 \Delta \mathrm{C}$ was unable to activate the enhancer (Figure 5F).

$P d x 1$ physically interacts and cooperates with Hnf6 to regulate Ngn3 enhancer activity. Previous reports demonstrate that $\mathrm{Hnf6}^{-/-}, \mathrm{Hnfl} \mathrm{b}^{-/-}$, and Sox $9^{+/-}$mice display decreased Ngn3 expression (46-48). Hnf6 


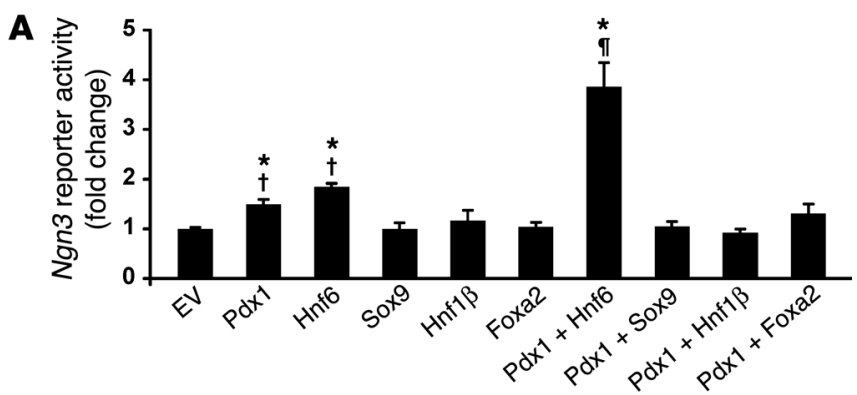

B

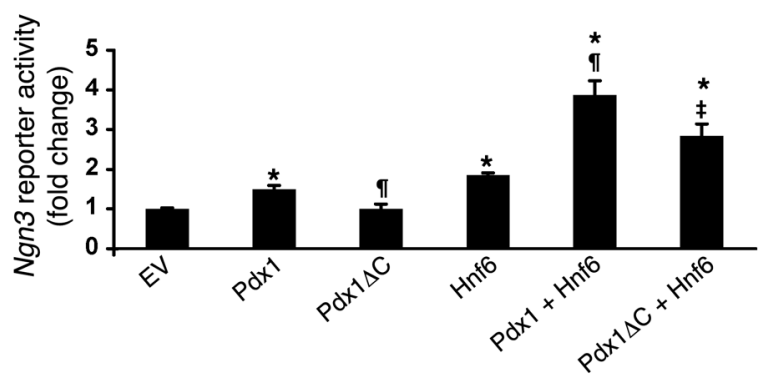

C

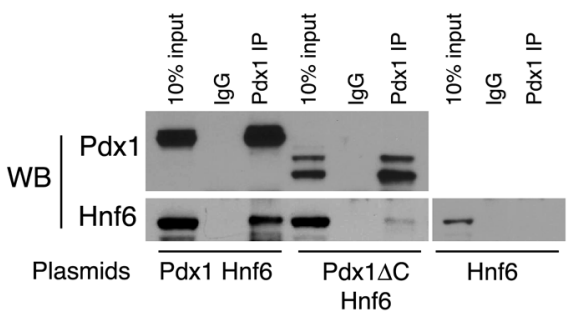

D

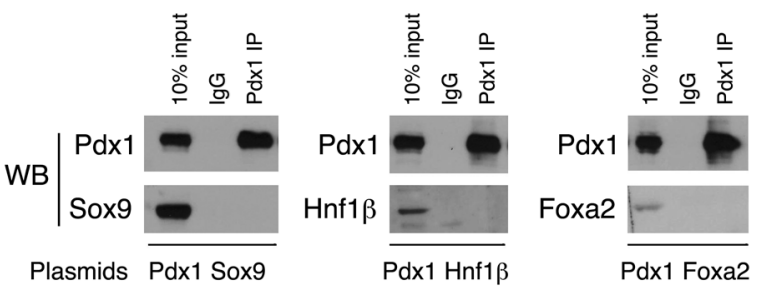

$\mathbf{E}$

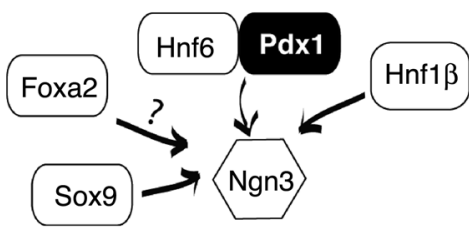

Figure 6

Pdx1 cooperates with Hnf6 to regulate Ngn3. HepG2 cells transfected with enhancer reporter Ngn3(-3379 to -3227)-tkluc and expression vectors for Pdx1, Hnf6, Sox9, Foxa2 (A) or Pdx1, Pdx1 $\Delta$ C, and Hnf6 (B). ${ }^{*} P<0.05$ versus empty vector; ${ }^{\dagger} P<0.01$ versus $\mathrm{Pdx} 1$ plus Hnf6; I $P<0.01$ versus $\mathrm{Pdx} 1 ; \neq P<0.05$ versus $\mathrm{Pdx} 1$ plus Hnf6. $n=4$. (C and D) Pdx1 physically interacts with Hnf6. 293T cells were transfected with expression vectors for $\mathrm{Pdx} 1$ or $\mathrm{Pdx} 1 \Delta \mathrm{C}$ and $\mathrm{Hnf} 6(\mathbf{C})$ or $\mathrm{Pdx} 1$ and Sox9, Hnf1 $\beta$, or Foxa2 (D). Cell lysates were immunoprecipitated with mouse monoclonal Pdx1 antisera or mouse IgG control. Western blots (WBs) using polyclonal antisera for Pdx1, Hnf6, Sox9, Hnf1 $\beta$, and Foxa2 are shown. A representative example of 3 independent experiments is shown. (E) Model depicting the role of Pdx1 in the transcriptional regulation of Ngn3. The question mark denotes the absence of in vivo evidence to support the in vitro studies, suggesting Foxa2mediated regulation of $\mathrm{Ngn} 3$.

To determine whether Pdx1 can interact with Hnf6, we cotransfected 293 T cells with plasmids expressing Pdx1 and Hnf6. Immunoprecipitation with $\mathrm{Pdx} 1$ antisera, followed by Western blot analysis with Hnf6 antisera, revealed a physical association between Pdx1 and Hnf6 (Figure 6C). This interaction was attenuated by truncation of the $\mathrm{C}$ terminus, indicating a role for the $\mathrm{C}$ terminus in the $\mathrm{Pdx} 1 / \mathrm{Hnf} 6$ association. The residual interaction between Pdx1 $\Delta C$ and Hnf6 points to either the Pdx1 N terminus or the central homeobox as additional domains mediating this association. When Pdx1 was co-transfected with plasmids encoding Sox9, Hnf1 $\beta$, or FoxA2, Pdx1 antisera did not immunoprecipitate any of these factors (Figure 6D), providing additional evidence for the specificity of the Pdx1/Hnf6 association. Thus, Pdx1 and Hnf6 could interact both physically and functionally to regulate Ngn3 promoter activity (Figure 6E), and this interaction was mediated at least in part by the Pdx1 C-terminal domain.

$P d x 1$ coordinates the transcriptional network of the developing pancreas. We also measured the expression of other transcription factors and pathways previously described to regulate $\mathrm{Ngn} 3$ using quantitative real-time PCR. During early pancreas development, activation of the Notch signaling pathway in Pdx1-expressing progenitors stimulates hairy and enhancer of split 1 (Hes1) expression, which in turn inhibits expression of $\mathrm{Ngn} 3$, thereby promoting self-renewal of progenitor cells and inhibiting endocrine differentiation (18, $21,49,50)$. In parallel to the Notch pathway, Gdf11, a member of the TGF- $\beta$ ligand family, also inhibits development of $\mathrm{Ngn}^{+}$islet progenitors $(51,52)$. Conversely, the transcription factors Hnf1 $\beta$, Foxa2, Hnf6, and Sox 9 have been identified as transcriptional activators of $\operatorname{Ngn} 3(22,39,43,47,53-58)$.

Transcript levels of Hes 1 and Gdf11 were normal in $P d x 1^{\Delta C / \Delta C}$ mice at E13.5. In contrast, we observed an approximately $50 \%$ reduction in Hnf6, Sox9, Foxa2, and Hnf1b mRNA levels (Figure 7A), indicating that these genes are downstream of $\mathrm{Pdx} 1$. This is a surprising observation since both Foxa2 and Hnf6 are reported to be upstream regulators of $P d x 1(55,57,59)$. Thus, our results suggest that $P d x 1$ is a member of the recently described cross-regulatory network, involving Hnf6, Sox9, Hnf1 $\beta$, and Foxa2 (22). To determine whether Pdx1 directly regulates Sox $9, \operatorname{Hnf1b}$, Hnf6, or Foxa2, we examined the results of high-throughput DNA sequencing of MIN6 insulinoma cell chromatin (ChIPSeq) immunoprecipitated with anti-Pdx1 antiserum. Sites in the proximal promoters of the Hnflb and Foxa2 genes were enriched, while no sites were enriched in the Sox9 and Hnf6 promoters (J. Yang and D.A. Stoffers, unpublished observa- 

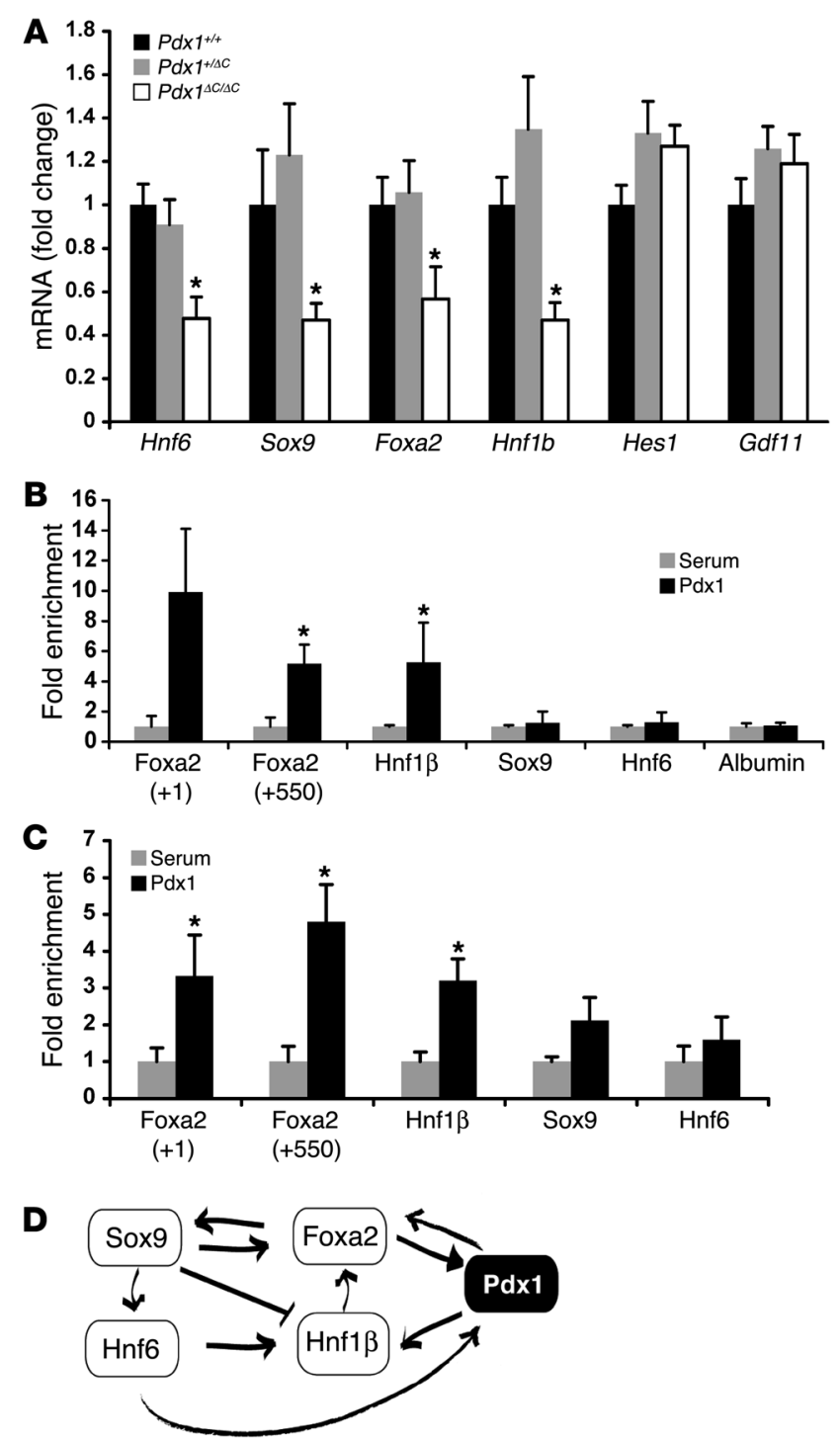

tions). These findings were confirmed in 3 independent MIN6 ChIP assays (Figure $7 \mathrm{~B}$ ). To determine whether $\mathrm{Pdx} 1$ also occupies these sequences during pancreas development, we performed Pdx1 ChIP assays using chromatin prepared from E13.5 pancreata. Pdx1 occupancy was enriched at the same conserved regulatory sequences of both the Hnf1b and Foxa2 genes (Figure 7C), suggesting that Pdx1 participated in the Hnf6, Sox9, Hnf1 $\beta$, Foxa2 transcription factor cross-regulatory network by directly regulating Hnf $1 \beta$ and Foxa2 promoters in a progenitor pool at E13.5 (Figure 7D).

Taken together, these studies indicate that $\mathrm{Pdx} 1$ contributed to the specification of pancreatic endocrine progenitors by participating in the Hnf6, Sox 9 , Hnf1 $\beta$, Foxa 2 transcription factor crossregulatory network and by regulating Ngn3 directly. Moreover, the $\mathrm{Pdx} 1 \mathrm{C}$ terminus may contribute to $\mathrm{Ngn} 3$ regulation independent of $\mathrm{Pdx} 1$ protein expression level through its role in the physical interaction of $\mathrm{Pdx} 1$ with Hnf6.

\section{Discussion}

In this study, we identified a direct role for $\mathrm{Pdx} 1$ in the specification of $\mathrm{Ngn}^{+}$endocrine progenitors. We discovered that Pdx1 con-

\section{Figure 7}

Pdx1 participates in a cross-regulatory network with Sox9, Hnf6, Foxa2, and Hnf1 $\beta$. (A) mRNA levels in total pancreas from $P d x 1^{+/+}$, $P d x 1^{+/ \Delta C}$, and $P d x 1^{\Delta C / \Delta C}$ pancreata at E13.5 ( $n=7-9$ per genotype; ${ }^{*} P<0.05$ ). (B and $\mathbf{C}$ ) ChIP with $\mathrm{Pdx} 1$ antisera of Min6 mouse insulinoma cells (B) or wild-type E13.5 pancreata (C). Two peaks of enrichment confirmed at +1 and +550 relative to the transcriptional start site of the Foxa2 gene and 1 peak at $-31,087$ relative to the transcriptional start site of the Hnf1b gene $\left(n=3 ;{ }^{*} P<0.05\right)$. (D) Model depicting the role of $\mathrm{Pdx} 1$ in the cross-regulatory transcription factor network governing early pancreas development.

tributes to the specification of endocrine progenitors by regulating $\mathrm{Ngn3}$ directly and in concert with $\mathrm{Hnf6}$ and by participating in a cross-regulatory transcription factor network during early pancreas development. Our data indicated that (a) Pdx1 plays a specific role in the emergence of pancreatic endocrine progenitors, in addition to being essential for overall pancreas organogenesis and (b) the role of Ngn3 in giving rise to hormone-expressing cells during the secondary transition is dependent upon $\mathrm{Pdx} 1$. Our results are supported by a recent study that describes the absence of $\mathrm{Ngn}^{+}$cells specifically during the secondary transition in $P d x 1^{-/-}$mice (60).

We identified Pdx1 as a member of the cross-regulatory network involving Hnf6, Foxa2, Hnf1 $\beta$, and Sox9. The combined defects in expression of $\operatorname{Hnf6}$, Foxa2, $\operatorname{Hnf} 1 \beta$, Sox9, and $\mathrm{Pdx} 1$ observed in $P d x 1^{\Delta C / \Delta C}$ mice likely influence $N g n 3$ expression in this model. We determined that Pdx1 directly occupies sequences in both Hnf1b and Foxa2 genes at E13.5. Thus, the position of Pdx1 both upstream of Foxa2, Hnf6, Sox9, and Hnf1 $\beta$ and downstream of Foxa 2 and Hnf6 indicates that Pdx1 participates in the recently described cross-regulatory network involving these transcription factors (22). In contrast, at this stage of pancreas development, $\mathrm{Pdx} 1$ does not participate in the network involving $\mathrm{Hnf} 1 \alpha$ and $\mathrm{Hnf} 4 \alpha$ (61), since mRNA levels of Hnf1a and $H n f 4 a$ were not altered in $P d x 1^{\Delta C / \Delta C}$ mice. The occupancy of the Ngn3 promoter by Pdx1 adjacent to potential binding sites for Hnf1, Foxa2, and Hnf6 is similar to enhancer regions that regulate expression of $\operatorname{Pdx} 1(39,45,53,54)$, suggesting the existence of conserved transcriptional regulatory modules that direct gene expression in the endocrine pancreas.

In addition to identifying a direct regulation of Foxa2 and $H n f 1 b$ by $\mathrm{Pdx} 1$, we identified $\mathrm{Hnf} 6$ as a protein partner for Pdx1, highlighting the complex role of $\mathrm{Pdx} 1$ in the transcriptional network of endocrine progenitors. Our data suggested that Pdx1 and Hnf6 cooperate to regulate $\mathrm{Ngn} 3$ expression. The importance of the Pdx1 C terminus in this interaction is demonstrated by the attenuated functional and physical interaction observed when the $\mathrm{C}$ terminus is truncated. However, the Pdx1 C-terminal deletion did not abolish the interaction between Pdx1 and Hnf6, indicating that other $\mathrm{Pdx} 1$ domains are also required. These findings suggested that the Pdx1 C terminus enhances the Pdx1/Hnf6 association by directly interacting with $\mathrm{Hnf} 6$ and/or by changing the conformation of other interacting regions. Alternatively, additional C-terminal-interacting protein partners may be required for Ngn3 regulation. Truncation of the $\mathrm{C}$ terminus is also predicted to disrupt the interaction of Pdx1 with Pcif1 and Meis2, nuclear factors whose roles in pancreas development are yet to be determined $(36,37)$. Several human C-terminal mutations are associated with reduced transactivation in promoter/reporter assays. One of these mutations, E224K, is located in the PCIF1 interaction motif and abrogates PCIF1 interaction in reporter 
assays (38), but the remaining C-terminal mutations lie outside of the PCIF1 interaction motif. Future experiments involving the derivation and characterization of mice harboring C-terminal mutations that selectively disrupt interaction with specific protein partners as well the identification and characterization of novel protein partners will advance our understanding of the mechanism whereby $\mathrm{Pdx} 1$ regulates endocrine progenitors.

Our finding that $\mathrm{Pdx} 1$ directly regulated $\mathrm{Ngn} 3$ is consistent with several reports in which induction of $\mathrm{Pdx} 1$ expression results in increased Ngn3 expression. Pdx1 overexpression in ES cells or human bone marrow-derived mesenchymal cells induces Ngn3 expression and promotes differentiation into insulin-producing cells $(8,62)$. Furthermore, recent protocols for in vitro differentiation of human ES cells into insulin-producing cells reveal increased Ngn3 expression following Pdx1 induction $(8,10)$. Our results provide a molecular explanation for this regulatory relationship, thereby providing insight into the requirements for manipulating multipotent cells to generate insulin-producing cells.

Recognition of the regulatory network of endocrine progenitors may be critical for guiding the differentiation of ES cells into robust $\beta$ cells as well as for the transdifferentiation of mature cell types for eventual translational application. Similar strategies could be envisioned for fostering the transition of induced pluripotent stem cells into $\beta$ cells. Our studies directly linking Pdx1 with $\mathrm{Ngn} 3$ expression and the transcription factor network of endocrine progenitors also suggest a mechanism whereby human $P d x 1$ mutations lead to diabetes.

\section{Methods}

Animals. To generate $P d x 1^{\Delta C / \Delta C}$ mice, the targeting vector was constructed by subcloning $2 \mathrm{XbaI}$ fragments $(8.0 \mathrm{~kb}$ and $2.8 \mathrm{~kb})$ containing $4 \mathrm{~kb}$ of the $5^{\prime}$ flanking region, exon 1 , intron 1 , exon 2 , and 3 ' sequences (25) of the $P d x 1$ locus from a mouse SV129 $\lambda$ FIXII bacteriophage clone. The Ser210 to termination codon mutation, along with a diagnostic BclI site, was introduced by overlap PCR. Neomycin resistance-thymidine kinase (Neo ${ }^{\mathrm{R}}$-tk) and diphtheria toxin A selection cassettes were inserted (Figure 1A). Targeted ES cell clones were injected into blastocysts by the University of Pennsylvania Transgenic and Chimeric Mouse Facility. Chimeric males were bred to SV129 females to achieve germ-line transmission. The resulting offspring were bred to C57BL/6, and all studies were performed on F3 offspring. To detect BrdU incorporation, pregnant mothers were pulsed with BrdU for 1 hour $(0.5 \mathrm{mg} / \mathrm{kg}$ body weight). Blood glucose levels were measured using a handheld glucometer (FreeStyle). $P d x 1^{+/-}$mice on a Black Swiss genetic background were obtained from C. Wright (Vanderbilt University, Nashville, Tennessee, USA) and backcrossed for 9 generations onto a C57BL/6 background. All procedures were approved by the Institutional Animal Care and Use Committee of the University of Pennsylvania. Intraperitoneal glucose tolerance tests were performed after a 6-hour fast using 2 g glucose $/ \mathrm{kg}$ body weight. Insulin levels were measured from whole blood collected at 0 and 5 minutes after intraperitoneal glucose injection ( 2 g glucose $/ \mathrm{kg}$ body weight). Plasma insulin was measured by ELISA (Crystal Chem Inc.).

Cell culture. All cell lines were cultured in a humidified chamber at $37^{\circ} \mathrm{C}$ and $5 \% \mathrm{CO}_{2}$. Baby hamster kidney cells were grown in DMEM medium (Invitrogen) with $10 \%$ FBS (Gemini) and 1X penicillin-streptomycin (Invitrogen). HepG2 cells were cultured in MEM media (Invitrogen) with 10\% FBS (Gemini), 1X penicillin-streptomycin (Invitrogen), and nonessential amino acids (Invitrogen). PDCs were grown as described previously (36). Pdx1 was overexpressed by retroviral transduction in primary mouse PDCs, as described previously (63).

RNA isolation and analysis. Total RNA was isolated from more than 10 cultured islets or individual E13.5/P1 pancreata using TRIzOL (Invitrogen) and the RNeasy kit (Qiagen). Integrity was confirmed on an Agilent Bioanalyzer. cDNA was generated using the SuperScript II Reverse Transcriptase kit (Invitrogen), and SYBR Green-based Real-Time Quantitative PCR (iQ5 iCycler and reagents; Bio-Rad) was used to measure mRNA levels. All values were normalized to HPRT mRNA levels and expressed as fold change compared with wild-type mice. Primer sequences are included in Supplemental Table 2 .

Western blotting. Individual pancreata from E13.5 animals were sonicated in lysis buffer (50 mM Tris-Cl, pH 7.8, 2\% SDS, 10\% glycerol, $10 \mathrm{mM} \mathrm{Na}_{4} \mathrm{P}_{2} \mathrm{O}_{7}, 100 \mathrm{mM} \mathrm{NaF}, 6 \mathrm{M}$ urea, $10 \mathrm{mM}$ EDTA). Protein $(1 \mu \mathrm{g})$ was resolved on $4 \%-12 \%$ NuPage Bis-Tris gels (Invitrogen) and transferred to nitrocellulose membranes. After blocking in $5 \%$ milk, membranes were incubated with rabbit anti-Pdx1 (1:10,000; a gift from C. Wright), followed by HRP-conjugated anti-rabbit antibody (1:10,000; Santa Cruz Biotechnology Inc.) and ECL Plus (GE Healthcare). Protein quantitation was determined using Bio-Rad ChemiDoc XRS and Quantity One software. Linearity was verified using a standard curve generated with varying amounts of wild-type E13.5 pancreas protein.

Immunostaining. Samples were fixed in $4 \%$ paraformaldehyde overnight at $4{ }^{\circ} \mathrm{C}$ and were paraffin-embedded, and $6 \mu \mathrm{m}$-thick sections were generated. After dewaxing, rehydrating, and blocking, slides were incubated with primary antibodies overnight at $4^{\circ} \mathrm{C}$ at the following dilutions: guinea pig anti-insulin (1:1,000; Linco), rabbit anti-glucagon (1:1,000; Biodesign), goat anti-glucagon (1:500; Santa Cruz Biotechnologies Inc.), goat antisomatostatin (1:1,000; Santa Cruz Biotechnology Inc.), rabbit anti-pancreatic polypeptide (1:15,000; Linco), rabbit anti-ghrelin (1:2,000; Phoenix Pharmaceuticals Inc.), sheep anti-BrdU (1:750; US Biological), rabbit antiKi67 (1:3,000; Vector Laboratories), rabbit anti-Pdx1 N terminus (1:10,000; a gift from C. Wright), goat anti-Pdx1 (1:10,000; a gift from C. Wright), rabbit anti-Pdx1 C terminus (1:1,000; a gift from J. Habener, Massachusetts General Hospital, Boston, Massachusetts, USA), goat anti-Pdx1 A17 (1:500; Santa Cruz Biotechnology Inc.), rabbit anti-Ngn3 (1:250; ref. 64), and mouse monoclonal anti-Ngn3 (1:500-1:3,000; Developmental Studies Hybridoma Bank). For light microscopy, HRP-conjugated secondary antisera (Vector Laboratories) were used and visualized with diaminobenzidine and a hematoxylin counterstain. For immunofluorescence, the signal was visualized with Cy2- and Cy3-conjugated secondary antisera (Jackson ImmunoResearch Laboratories Inc.). For TUNEL staining, the ApopTag detection kit (catalog no. S7100; Chemicon) was used with Cy3-conjugated mouse anti-digoxigenin (Jackson ImmunoResearch Laboratories Inc.). Images were captured using a Nikon Eclipse E600 microscope with a CoolSNAP camera (Photometrics). All area measurements and cell counting were performed with IVision Software (BioVision Inc.).

ChIP. ChIP assay and its analysis was performed as described previously (36), with a few modifications. For E13.5 pancreas ChIP, 60-100 pancreata were isolated from CD1 E13.5 embryos and crosslinked immediately in $1 \%$ formaldehyde. Following quenching in $125 \mathrm{mM}$ glycine, samples were resuspended in cell lysis buffer and were homogenized and spun. The pellet was resuspended in nuclear lysis buffer and sonicated with a Bioruptor to generate 200-300 bp DNA fragments. Relative enrichment was determined using quantitative real-time PCR. Values were compared with input serial dilutions and are expressed as fold enrichment compared with isotype matched nonimmune serum samples.

Promoter reporter assays. The Ngn3 enhancer $(-3,379$ to $-3,227)$ was amplified using PCR from mouse genomic DNA and cloned into the BamHI and SacI sites of a thymidine kinase minimal promoter luciferase reporter plasmid (a gift from E. Suh, University of Pennsylvania). Reporter assays were performed as described previously (37). Ngn3-minimal thymidine kinase promoter-luciferase (Ngn3-tkluc) or (TAAT1) -65 somatosatin promoter-chloramphenicol acetyltransferase (SMS-CAT) and expres- 
sion plasmids pCMX-Pdx1, pCMX-Pdx1(1-210), pHD-Foxa2 (a gift from K. Kaestner), pCMV4-Hnf6 (gift from M. Gannon, Vanderbilt University), pCB6-Hnf1 $\beta$ (a gift from M. Sander, UCSD, San Diego, California, USA), and PCDNA3-Sox9 (a gift from M. Sander), and a $\beta$-galactosidase internal control plasmid were cotransfected into HepG2 or baby hamster kidney cells with Lipofectamine 2000 (Invitrogen), and the cells were harvested 48 hours later. Luciferase (Promega) or CAT activity was measured and normalized to $\beta$-galactosidase activity. Protein expression of Pdx1 and Pdx1(1-210) was measured by Western blotting to quantitate expression levels. Normalized reporter activity from cells expressing equivalent levels of $\mathrm{Pdx} 1$ and $\mathrm{Pdx} 1(1-210)$ protein were compared.

Coimmunoprecipitations. 293T cells were seeded in 100-mm culture dishes and transfected with 500 ng of pCMX-Pdx1, pCMX-Pdx1(1-210), pCMVHnf6, Hnf1 $\beta$, or Sox9 plasmids using Lipofectamine 2000 (Invitrogen). Cell were harvested 2 days later in lysis buffer $(50 \mathrm{mM}$ Tris-Cl, $\mathrm{pH} 7.5,1 \%$ $\mathrm{NP} 40,100 \mathrm{mM} \mathrm{NaCl}$, and protease inhibitor cocktail [Chemicon]). Lysate was precleared by rotating at $4^{\circ} \mathrm{C}$ for 2 hours with Protein $\mathrm{G}$ agarose beads (GE Healthcare). Following a brief centrifugation to remove beads, lysates were incubated at $4{ }^{\circ} \mathrm{C}$ overnight with $2 \mu \mathrm{g}$ of $\mathrm{Pdx} 1$ monoclonal antibody (R\&D Systems) or mouse IgG control (Santa Cruz Biotechnology Inc.), followed by a 2 -hour, $4^{\circ} \mathrm{C}$ incubation with $50 \mu \mathrm{l}$ of Protein $\mathrm{G}$ agarose beads. Beads were briefly centrifuged and washed with fresh lysis buffer 5 times. Bound proteins were eluted with 2 X SDS-PAGE buffer and analyzed by Western blotting using the following antibodies: rabbit anti-Pdx1 N terminus (1:10,000; a gift from C. Wright), rabbit anti-Hnf6 (1:500; Santa Cruz Biotechnology Inc.), rabbit anti-Sox9 (1:2,000; Chemicon), goat antiHnf1ß (1:500; Santa Cruz Biotechnology Inc.), and goat anti-Foxa2 (1:500; Santa Cruz Biotechnology Inc.).

Statistics. Values are expressed as mean \pm SEM and were compared using 2 -tailed Student's $t$ tests. $P$ values of less than 0.05 are considered statistically significant.

1. Ferber, S., et al. 2000. Pancreatic and duodenal homeobox gene 1 induces expression of insulin genes in liver and ameliorates streptozotocininduced hyperglycemia. Nat. Med. 6:568-572.

2. Horb, M.E., Shen, C.N., Tosh, D., and Slack, J.M. 2003. Experimental conversion of liver to pancreas. Curr. Biol. 13:105-115.

3. Kojima, H., et al. 2003. NeuroD-betacellulin gene therapy induces islet neogenesis in the liver and reverses diabetes in mice. Nat. Med. 9:596-603.

4. Sapir, T., et al. 2005. Cell-replacement therapy for diabetes: Generating functional insulin-producing tissue from adult human liver cells. Proc. Natl. Acad. Sci. U. S. A. 102:7964-7969.

5. Zhou, Q., Brown, J., Kanarek, A., Rajagopal, J., and Melton, D.A. 2008. In vivo reprogramming of adult pancreatic exocrine cells to beta-cells. Nature. 455:627-632.

6. Phillips, B.W., et al. 2007. Directed differentiation of human embryonic stem cells into the pancreatic endocrine lineage. Stem Cells Dev. 16:561-578.

7. Shim, J.H., et al. 2007. Directed differentiation of human embryonic stem cells towards a pancreatic cell fate. Diabetologia. 50:1228-1238.

8. Jiang, J., et al. 2007. Generation of insulin-producing islet-like clusters from human embryonic stem cells. Stem Cells. 25:1940-1953.

9. D'Amour, K.A., et al. 2005. Efficient differentiation of human embryonic stem cells to definitive endoderm. Nat. Biotechnol. 23:1534-1541.

10. D'Amour, K.A., et al. 2006. Production of pancreatic hormone-expressing endocrine cells from human embryonic stem cells. Nat. Biotechnol. 24:1392-1401.

11. Kroon, E., et al. 2008. Pancreatic endoderm derived from human embryonic stem cells generates glucose-responsive insulin-secreting cells in vivo. Nat. Biotechnol. 26:443-452.

\section{Acknowledgments}

We thank U. Jhala, C.L. May, K. Tremblay, and members of the Stoffers laboratory for critically reading this manuscript. We are grateful to C. Wright for providing $P d x 1^{+/-}$mice, $\mathrm{Pdx} 1$ antisera, and helpful discussions. We thank G. Swain (Morphology Core, University of Pennsylvania School of Medicine) for his morphology expertise, D. Groff for breeding and genotyping, L. Sussel and J. LeLay for ChIP advice, and M. Wescott and A.J. von Burstin in the Rustgi laboratory for providing PDCs. Ngn3 antibody was obtained from the Developmental Studies Hybridoma Bank (National Institute of Child Health and Human Development and The University of Iowa). This work was supported by NIH grants R01 DK068157 (to D.A. Stoffers), P01 DK49210 (to D.A. Stoffers and K.H. Kaestner), and R01 DK060694 (to A.K. Rustgi and D.A. Stoffers) and NIH predoctoral National Research Service Award 5F31HL071273 (to J.M. Oliver-Krasinski) and was facilitated by the Morphology Core of the Center for Molecular Studies in Digestive and Liver Disease, University of Pennsylvania (NIH P30 DK50306).

Received for publication August 4, 2008, and accepted in revised form April 2, 2009.

Address correspondence to: Doris A. Stoffers, Institute for Diabetes, Obesity and Metabolism, Department of Medicine, University of Pennsylvania School of Medicine, Clinical Research Building no. 700, 415 Curie Boulevard, Philadelphia, Pennsylvania 19104, USA. Phone: (215) 573-5413; Fax: (215) 898-5408; E-mail: stoffers@mail.med.upenn.edu.

Michael F. Crutchlow's present address is: Merck Research Laboratories, Merck \& Co. Inc., North Wales, Pennsylvania, USA.
12. Oliver-Krasinski, J.M., and Stoffers, D.A. 2008. On the origin of the beta cell. Genes Dev. 22:1998-2021.

13. Gradwohl, G., Dierich, A., LeMeur, M., and Guillemot, F. 2000. neurogenin 3 is required for the development of the four endocrine cell lineages of the pancreas. Proc. Natl. Acad. Sci. U. S. A. 97:1607-1611.

14. Schwitzgebel, V.M., et al. 2000. Expression of neurogenin3 reveals an islet cell precursor population in the pancreas. Development. 127:3533-3542.

15. Jensen, J., et al. 2000. Independent development of pancreatic alpha- and beta-cells from neurogenin3expressing precursors: a role for the notch pathway in repression of premature differentiation. Diabetes. 49:163-176.

16. Gu, G., Dubauskaite, J., and Melton, D.A. 2002. Direct evidence for the pancreatic lineage: NGN3+ cells are islet progenitors and are distinct from duct progenitors. Development. 129:2447-2457.

17. Johansson, K.A., et al. 2007. Temporal control of neurogenin 3 activity in pancreas progenitors reveals competence windows for the generation of different endocrine cell types. Dev. Cell. 12:457-465.

18. Apelqvist, A., et al. 1999. Notch signalling controls pancreatic cell differentiation. Nature. 400:877-881.

19. Prado, C.L., Pugh-Bernard, A.E., Elghazi, L., SosaPineda, B., and Sussel, L. 2004. Ghrelin cells replace insulin-producing beta cells in two mouse models of pancreas development. Proc. Natl. Acad. Sci. U. S. A. 101:2924-2929.

20. Heller, R.S., et al. 2005. Genetic determinants of pancreatic epsilon-cell development. Dev. Biol. 286:217-224.

21. Jensen, J., et al. 2000. Control of endodermal endocrine development by Hes-1. Nat. Genet. 24:36-44.

22. Lynn, F.C., et al. 2007. Sox9 coordinates a transcriptional network in pancreatic progenitor cells. Proc. Natl. Acad. Sci. U. S. A. 104:10500-10505.
23. Stoffers, D.A., Zinkin, N.T., Stanojevic, V., Clarke, W.L., and Habener, J.F. 1997. Pancreatic agenesis attributable to a single nucleotide deletion in the human IPF1 gene coding sequence. Nat. Genet. 15:106-110.

24. Jonsson, J., Carlsson, L., Edlund, T., and Edlund, H. 1994. Insulin-promoter-factor 1 is required for pancreas development in mice. Nature. 371:606-609.

25. Offield, M.F., et al. 1996. PDX-1 is required for pancreatic outgrowth and differentiation of the rostral duodenum. Development. 122:983-995.

26. Schwitzgebel, V.M., et al. 2003. Agenesis of human pancreas due to decreased half-life of insulin promoter factor 1. J. Clin. Endocrinol. Metab. 88:4398-4406.

27. Fujitani, Y., et al. 2006. Targeted deletion of a cis-regulatory region reveals differential gene dosage requirements for Pdx1 in foregut organ differentiation and pancreas formation. Genes Dev. 20:253-266.

28. Holland, A.M., Hale, M.A., Kagami, H., Hammer, R.E., and MacDonald, R.J. 2002. Experimental control of pancreatic development and maintenance. Proc. Natl. Acad. Sci. U. S. A. 99:12236-12241.

29. Herrera, P.L. 2000. Adult insulin- and glucagonproducing cells differentiate from two independent cell lineages. Development. 127:2317-2322.

30. Ham, J.N., and Stoffers, D.A. 2009. Role of Pdx1 in beta cell growth. In Islet cell growth factors. R.N. Kulkarni, editor. Landes Bioscience. Austin, Texas, USA. In press.

31. Weng, J., et al. 2001. Functional consequences of mutations in the MODY4 gene (IPF1) and coexistence with MODY3 mutations. Diabetologia. 44:249-258.

32. Hani, E.H., et al. 1999. Defective mutations in the insulin promoter factor-1 (IPF-1) gene in late-onset type 2 diabetes mellitus. J. Clin. Invest. 104:R41-R48.

33. Cockburn, B.N., et al. 2004. Insulin promoter fac- 
tor- 1 mutations and diabetes in Trinidad: identification of a novel diabetes-associated mutation (E224K) in an Indo-Trinidadian family. J. Clin. Endocrinol. Metab. 89:971-978.

34. Lu, M., Miller, C., and Habener, J.F. 1996. Functional regions of the homeodomain protein IDX-1 required for transactivation of the rat somatostatin gene. Endocrinology. 137:2959-2967.

35. Peers, B., Leonard, J., Sharma, S., Teitelman, G., and Montminy, M.R. 1994. Insulin expression in pancreatic islet cells relies on cooperative interactions between the helix loop helix factor E47 and the homeobox factor STF-1. Mol. Endocrinol. 8:1798-1806

36. Deramaudt, T.B., et al. 2006. The PDX1 homeodomain transcription factor negatively regulates the pancreatic ductal cell-specific keratin 19 promoter. J. Biol. Chem. 281:38385-38395.

37. Liu, A., Desai, B.M., and Stoffers, D.A. 2004. Identification of PCIF1, a POZ domain protein that inhibits PDX-1 (MODY4) transcriptional activity. Mol. Cell. Biol. 24:4372-4383.

38. Liu, A., Oliver-Krasinski, J., and Stoffers, D.A. 2006. Two conserved domains in PCIF1 mediate interaction with pancreatic transcription factor PDX-1. FEBS Lett. 580:6701-6706.

39. Gerrish, K., Cissell, M.A., and Stein, R. 2001. The role of hepatic nuclear factor 1 alpha and PDX-1 in transcriptional regulation of the $\mathrm{pdx}-1$ gene. J. Biol. Chem. 276:47775-47784.

40. Chakrabarti, S.K., James, J.C., and Mirmira, R.G. 2002. Quantitative assessment of gene targeting in vitro and in vivo by the pancreatic transcription factor, Pdx1. Importance of chromatin structure in directing promoter binding. J. Biol. Chem. 277:13286-13293.

41. Brissova, M., et al. 2002. Reduction in pancreatic transcription factor PDX-1 impairs glucose-stimulated insulin secretion. $J$. Biol. Chem . 277:11225-11232.

42. Johnson, J.D., et al. 2003. Increased islet apoptosis in $\mathrm{Pdx} 1+/-$ mice. J. Clin. Invest. 111:1147-1160.

43. Lee, J.C., et al. 2001. Regulation of the pancreatic pro-endocrine gene neurogenin3. Diabetes.
50:928-936.

44. Smith, S.B., Watada, H., Scheel, D.W., Mrejen, C., and German, M.S. 2000. Autoregulation and maturity onset diabetes of the young transcription factors control the human PAX4 promoter. J. Biol. Chem. 275:36910-36919.

45. Gerrish, K., Van Velkinburgh, J.C., and Stein, R. 2004. Conserved transcriptional regulatory domains of the pdx-1 gene. Mol. Endocrinol. 18:533-548.

46. Haumaitre, C., et al. 2005. Lack of TCF2/vHNF1 in mice leads to pancreas agenesis. Proc. Natl. Acad. Sci. U. S. A. 102:1490-1495.

47. Jacquemin, P., et al. 2000. Transcription factor hepatocyte nuclear factor 6 regulates pancreatic endocrine cell differentiation and controls expression of the proendocrine gene ngn3. Mol. Cell. Biol. 20:4445-4454

48. Seymour, P.A., et al. 2008. A dosage-dependent requirement for Sox9 in pancreatic endocrine cell formation. Dev. Biol. 323:19-30.

49. Hald, J., et al. 2003. Activated Notch1 prevents differentiation of pancreatic acinar cells and attenuate endocrine development. Dev. Biol. 260:426-437.

50. Murtaugh, L.C., Stanger, B.Z., Kwan, K.M., and Melton, D.A. 2003. Notch signaling controls multiple steps of pancreatic differentiation. Proc. Natl. Acad. Sci. U. S. A. 100:14920-14925.

51. Dichmann, D.S., Yassin, H., and Serup, P. 2006 Analysis of pancreatic endocrine development in GDF11-deficient mice. Dev. Dyn. 235:3016-3025.

52. Harmon, E.B. et al. 2004. GDF11 modulates NGN3+ islet progenitor cell number and promotes beta-cell differentiation in pancreas development. Development. 131:6163-6174.

53. Gerrish, K., et al. 2000. Pancreatic beta cell-specific transcription of the $\mathrm{pdx}-1$ gene. The role of conserved upstream control regions and their hepatic nuclear factor 3beta sites. J. Biol. Chem. 275:3485-3492.

54. Samaras, S.E., et al. 2002. Conserved sequences in a tissue-specific regulatory region of the $\mathrm{pdx}-1$ gene mediate transcription in Pancreatic beta cells: role for hepatocyte nuclear factor 3 beta and Pax6. Mol. Cell. Biol. 22:4702-4713.
55. Wu, K.L., et al. 1997. Hepatocyte nuclear factor 3 beta is involved in pancreatic beta-cell-specific transcription of the pdx-1 gene. Mol. Cell. Biol. 17:6002-6013

56. Poll, A.V., et al. 2006. A vHNF1/TCF2-HNF6 cascade regulates the transcription factor network that controls generation of pancreatic precursor cells. Diabetes. 55:61-69.

57. Wilding, L., and Gannon, M. 2004. The role of $\mathrm{pdx} 1$ and HNF6 in proliferation and differentiation of endocrine precursors. Diabetes Metab. Res. Rev. 20:114-123.

58. Jacquemin, P., Lemaigre, F.P., and Rousseau, G.G. 2003. The Onecut transcription factor HNF-6 (OC-1) is required for timely specification of the pancreas and acts upstream of Pdx- 1 in the specification cascade. Dev. Biol. 258:105-116.

59. Lee, C.S., et al. 2002. Foxa 2 controls Pdx1 gene expression in pancreatic beta-cells in vivo. Diabetes. 51:2546-2551.

60. Burlison, J.S., Long, Q., Fujitani, Y., Wright, C.V., and Magnuson, M.A. 2008. Pdx-1 and Ptf1a concurrently determine fate specification of pancreatic multipotent progenitor cells. Dev. Biol. 316:74-86.

61. Boj, S.F., Parrizas, M., Maestro, M.A., and Ferrer, J. 2001. A transcription factor regulatory circuit in differentiated pancreatic cells. Proc. Natl. Acad. Sci. U. S. A. 98:14481-14486.

62. Miyazaki, S., Yamato, E., and Miyazaki, J. 2004. Regulated expression of $\mathrm{pdx}-1$ promotes in vitro differentiation of insulin-producing cells from embryonic stem cells. Diabetes. 53:1030-1037.

63. Deramaudt, T.B., et al. 2006. N-cadherin and keratinocyte growth factor receptor mediate the functional interplay between Ki-RASG12V and p53V143A in promoting pancreatic cell migration, invasion, and tissue architecture disruption. $\mathrm{Mol}$. Cell. Biol. 26:4185-4200.

64. Lee, C.S., De León, D.D., Kaestner, K.H., and Stoffers, D.A. 2006. Regeneration of pancreatic islets after partial pancreatectomy in mice does not involve the reactivation of neurogenin-3. Diabetes. 55:269-272. 